Saudi Journal of Biomedical Research

Abbreviated Key Title: Saudi J Biomed Res ISSN 2518-3214 (Print) |ISSN 2518-3222 (Online)

\title{
Physicochemical, Microbiological and Sensory Characterization of Juice Produced from Watermelon (Citrullus lanatus) Consumed in Côte d'Ivoire
}

\author{
Combo Agnan Marie-Michel*, Niaba Koffi Pierre Valery, Ekissi Alice Christine, Kouame Gnakri Amah Salomée,
} Beugre Grah Avit Maxwell

Department of Biochemistry-Microbiology, Laboratory of Agrovalorization, Jean Lorougnon Guédé University, BP 150 Daloa, Côte d'Ivoire

DOI: $\underline{10.36348 / \text { sjbr.2020.v05i11.009 }}$

| Received: 08.11.2020 | Accepted: 19.11.2020 | Published: 23.11.2020

*Corresponding author: Combo Agnan Marie-Michel

Abstract

Watermelon (Citrullus lanatus) is one of the most commonly consumed tropical fruits by humans, especially Ivorians. The present study was initiated to evaluate the physicochemical, microbiological and sensory properties of watermelon juice produced in an artisanal way. For this purpose, the effect of pasteurization $\left(82^{\circ} \mathrm{C}\right.$ for $\left.20 \mathrm{~s}\right)$ and storage $\left(8^{\circ} \mathrm{C}\right.$ for four days) on different parameters were evaluated. The $\mathrm{pH}$ decreases from 4.83 to 3.78 (unpasteurized juice) and from 5.13 to 3.84 (pasteurized juice), the acidity increases from 0.09 to $0.34 \mathrm{~g} / \mathrm{L}$ (unpasteurized juice) and from 0.09 to $0.25 \mathrm{~g} / \mathrm{L}$ (pasteurized juice), the Brix values drop from 5.95 to $4.65^{\circ} \mathrm{B}$ (unpasteurized juice) and from 6 to $4.80^{\circ} \mathrm{B}$ (pasteurized juice), and the dry matter and reducing sugars respectively varied from 4.49 to $2.12 \%, 0.069$ to $0.06 \%$ (unpasteurized juice) and from 5.25 to $2.21 \%, 0.064$ to $0.06 \%$. No change was observed in the ash content in the two juices. It varied from 0.32 to $0.08 \%$. Regarding vitamin $\mathrm{C}$ and lycopene, the average contents were respectively $7.57 \mathrm{~g} / \mathrm{mL}$ and 0.055 $\mathrm{mg} / 100 \mathrm{~mL}$ (unpasteurized juice) and $2.45 \mathrm{~g} / \mathrm{mL}$ and $0.047 \mathrm{mg} / 100 \mathrm{~mL}$ (pasteurized juice). Microbiological analyzes of unpasteurized and pasteurized juices have shown the absence of coliforms and staphylococcus aureus. However, the number of mesophilic aerobic germs is lower than that of the standard. The sensory test shows that watermelon juice products have a good acceptance by the panelists. Finally, this study showed that heat treatment influences the antioxidant content and not the physicochemical parameters and ensures a healthy juice.

Keywords: Watermelon juice, drinks, pasteurization, physicochemical analyses, sanitary quality, Sensory evaluation, Lycopene, Vitamin C.

Copyright (C) 2020 The Author(s): This is an open-access article distributed under the terms of the Creative Commons Attribution 4.0 International License (CC BY-NC 4.0) which permits unrestricted use, distribution, and reproduction in any medium for non-commercial use provided the original author and source are credited.

\section{INTRODUCTION}

Fruits contain a significant number of antioxidants, minerals, vitamins and dietary fiber which are vital to human body. Thus, the consumption of fruits could help reduce the risk of many illnesses such as diabetes, cancer, cardiovascular diseases and other illnesses [1]. Furthermore, Consumers are increasingly aware of the health benefits of fruit and vegetable consumption. Low consumption of fruits and vegetables is the environmental cause for $31 \%$ of ischemic heart disease and $11 \%$ of stroke worldwide [2]. In fact, fresh or in the form of processed products, fruits have very attractive colors, tastes and aromas and they are an essential part of the diet. Fruits constitute an inexhaustible source of nutrients, the secondary metabolites of which are among the most important [3].

Watermelon a tropical fruit of the cucurbitaceae family whose scientific name is Citrullus lanatus, is widely consumed around the world. It grows in temperate and tropical climates, thrives in aerated soils rich in organic matter [4]. In 2012, watermelon occupied around $5.3 \%$ of the cultivated territories in terms of fruit in the world [5]. Watermelon is an excellent source of natural antioxidants, including lycopene, vitamin $\mathrm{C}$ and citrulline [6] which are beneficial in reducing cancer, cardiovascular disorders, diabetes, blood pressure, and obesity [7, 8]. Watermelon contains up to $92 \%$ water and other essential vitamins and minerals necessary for healthy growth and it plays a very important role in Africa as it is used to quench thirst when there is shortage of water [9]. It is a low-calorie dessert fruit, with sweet taste used mostly in salads and juice [10].

In Côte d'Ivoire, watermelon fruit occurs mainly around large cities for urban consumption and is carried out by small African market gardeners who cultivate small areas [11]. It is the object of several activities including marketing on local markets, where 
it is sold whole or in cut slices. Watermelon is a fruit highly prized for its sweet taste and its thirst-quenching flavor in some [12]. Despite its multiple uses and interesting nutritional characteristics, no industrial production of the juice has yet been carried out and no study has been devoted to the nutritional characterization of watermelon juice in Côte d'Ivoire. However, watermelon could be exploited for juice making such as passion fruit, orange, ginger, guava and others juices produced locally and seen on supermarkets shelves.

In order to take advantage of this potentially interesting resource, the present work aims to determine the physicochemical, microbiological and organoleptic characteristics of the watermelon juice extracted of which is produced locally in the southern region of Côte d'Ivoire for its valuation.

\section{MATERIALS ET METHODS Materials}

The plant material used in this work is the fruit of watermelon (Citrullus lanatus), of the Charlestone Gray variety. Fresh watermelon fruits were purchased at the local market of Gonzaqueville (Abidjan, Côte d'Ivoire). In Côte d'Ivoire, the fruits are sold whole or cut slices (Figure-1). All chemicals and reagents used were of analytical grade.

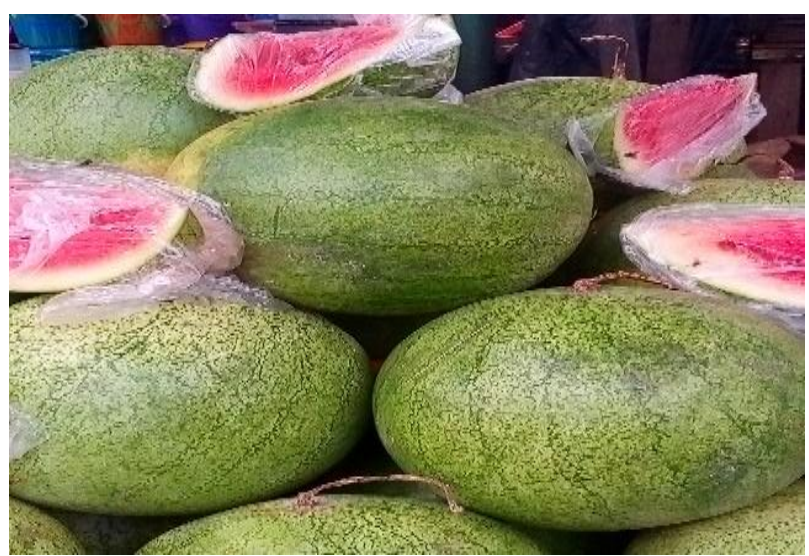

Fig-1: Watermelons of the Charlestone Gray variety

\section{Methods}

\section{Watermelon juice preparation and processing}

After purchase, the watermelon fruits were immediately transported to the National Public Health laboratory (Treichville, Abidjan, Côte d'Ivoire). The preparation of watermelon juice was carried out in several stages. Ripe watermelon fruits were washed with water to remove heavy soil, then rewashed in $1 / 10$ diluted bleach for $20 \mathrm{~min}$, then rinsed with clean water. Then followed the peeling which consisted of removing the skin covering the fruit with a kitchen knife (stainless steel) and the entire white outer flesh covering the red flesh (edible). This recovered pulpit was cut into several pieces (in cubes). Sufficient manual grinding was applied to them in order to extract as much juice as possible. The obtained liquid was sieved $(1 \mathrm{~mm})$ and filtered with six layers of cotton wool cloth under aseptic conditions. To limit microbial growth, thermal treatments are still used by most of the fruit juice processing due to their simplicity and efficiency. For it, one part of juice was pasteurized at $82^{\circ} \mathrm{C}$ for $20 \mathrm{~s}$ then cooled in a desiccator, while the unpasteurized sample served as the control. The bottled juices (pasteurized and unpasteurized) were stored under refrigeration temperature of $8^{\circ} \mathrm{C}$. The physicochemical parameters were analyzed every day for four days. The analysis of vitamin $\mathrm{C}$, lycopene, microbiological and sensory was carried out on the first day.

\section{Determination of the physicochemical parameters of watermelon juice \\ pH}

The determination of $\mathrm{pH}$ is the measurement of the acidity or alkalinity of a product. The $\mathrm{pH}$ measurement was performed with a $\mathrm{pH}$ meter by inserting the probe inside the sample, the result being read directly on the display of the device. The sample to be analyzed was brought to a temperature of around $20^{\circ} \mathrm{C}[13]$.

\section{Titratable acidity}

The titratable acidity of the juices, expressed as citric acid content per unit volume is determined by titrimetry using a sodium hydroxide solution $(0.1 \mathrm{~N})$, in the presence of $1 \%$ bromotymol blue as color indicator [14]. The acidity in the sample was obtained by taking into account the coefficient of citric acid which is equal to 6.4 , according to the following formula:

$$
\boldsymbol{T A}(g / L)=\frac{\left(N_{\mathrm{NaOH}} \times V_{\mathrm{NaOH}} \times 6.4\right)}{V_{\text {juice }}}
$$

\section{Refractometric dry extract}

The Brix value reflects the amount of sugar present in the juice expressed in terms of the percentage of the sucrose content. The sugar level is expressed in degrees Brix and is determined by measuring the refractive index using a refractometer. Indeed: $1^{\circ} \mathrm{Brix}$ is equivalent to $1 \mathrm{~g}$ of sugar in $100 \mathrm{~g}$ of the solution. A quantity of the product was brought into direct contact with the lens of the refractometer. The result is read on the screen of the refractometer (ISO 4833; 2003).

\begin{abstract}
Ashes
Total ash is the residue of mineral compounds that remains after incineration of a sample containing organic substances of plant, animal or synthetic origin. The ash content of watermelon juice has been determined according to the official method AOAC 972.15 [15]. An amount of $5 \mathrm{~g}$ of the sample was weighed in porcelain crucibles. The crucibles were then placed for 5 hours in a muffle furnace at $550^{\circ} \mathrm{C}$. On leaving the oven, the crucibles were cooled in a desiccator, before being weighed. The percentage of ash was calculated from the mass of the residue after
\end{abstract}


incineration. The ash content is given by the following formula:

$$
\% \boldsymbol{A s h}=\frac{m_{1}-m_{0}}{m_{e}} \times 100
$$

$\mathrm{m}_{\mathrm{o}}$ : mass $(\mathrm{g})$ of the empty crucible.

$\mathrm{m}_{\mathrm{e}}$ : mass $(\mathrm{g})$ of the sample.

$\mathrm{m}_{1}$ : mass $(\mathrm{g})$ of the whole (crucible + ash) after incineration

\section{Moisture and dry matter}

The determination of the water content of watermelon juice was carried out by the method of AOAC [14]. A quantity of $5 \mathrm{~g}$ of watermelon juice was weighed and placed in an oven at $105^{\circ} \mathrm{C}$ for $3 \mathrm{~h}$. Then the crucibles are removed from the oven and weighed after cooling in a desiccator. The humidity level was determined by the following formula:

$$
\% \text { Moisture }=\frac{\left(C_{v}+P_{e}\right)-\left(C_{v}+e\right)}{P_{e}} \times 100
$$

$\mathrm{C}_{\mathrm{V}}$ : mass $(\mathrm{g})$ of the empty crucible

$\mathrm{P}_{\mathrm{e}}$ : test sample $(\mathrm{g})$

e: mass $(\mathrm{g})$ of the dried sample

The dry matter is then estimated by calculation: \% Dry Matter $=100-\%$ Moisture

\section{Reducing Sugars}

The reducing sugars in juice were determined according to the method of Bernfeld [16]. using 3,5 dinitro-salicylic acid (DNS). A volume of $150 \mu \mathrm{l}$ of ethanosoluble extract was taken and placed in a test tube. To this volume, $300 \mu \mathrm{L}$ of DNS $(3,5$ dinitrosalicylic acid) was added. The mixture was brought to the boiling water bath for 5 minutes. Two milliliters of distilled water were added to the reaction medium after cooling for $5 \mathrm{~min}$ on the bench. The optical density reading was taken at $540 \mathrm{~nm}$ with the spectrophotometer against a control containing all the products except the ethanosoluble extract. The optical density was converted into the quantity of reducing sugars using a standard curve obtained from a glucose solution $(2 \mathrm{mg} / \mathrm{mL})$.

\section{HPLC/UV analysis of vitamin C and lycopene}

The ascorbic acid (vitamin C) content was determined by high performance liquid chromatography with UV- visible as detector. One $\mathrm{g}$ of each juice was mixed with $50 \mathrm{~mL}$ of pure methanol $(99,9 \%)$. The mixture obtained was filtered and diluted (1/10) with HPLC mobile phase. For the reference solution, $50 \mathrm{mg}$ of vitamin $\mathrm{C}$ was dissolved into $100 \mathrm{~mL}$ of methanol until complete dissolution. The rest of the protocol remains the same. $20 \mu \mathrm{L}$ of this material was injected into a HPLC system (Waters Inc., Milford, MA, USA) equipped with a RP8 reversed phase column (120 $\mathrm{mm} \times$ $3.9 \mathrm{~mm} \times 5 \mu \mathrm{m})$ and coupled on line with UV-visible detector. Elution was carried out with a solvent composed of $85 \%$ acetic acid (12\%) and $15 \%$ acetonitrile at ambient temperature and at a flow rate of
$1.3 \mathrm{~mL} / \mathrm{min}$. Vitamin $\mathrm{C}$ compounds were detected at $270 \mathrm{~nm}$

Lycopene was determined using the chromatography system HPLC Agilent 1100 series. The column was a Waters RP18 XterraTM $(250 \times 4,6 \mathrm{~mm} \times$ $5 \mu \mathrm{m})$ coupled to a Pre-colonne Waters RP18 XterraTM $(20 \times 3,9 \mathrm{~mm}$ i.d. $)$. The mobile phase consisted of solvent A (acetonitrile) and solvent B (bicarbonate buffer, $\mathrm{pH}=9.8$ ). The flow-rate was $1 \mathrm{~mL} / \mathrm{min}$ and the injection volume was $50 \mu \mathrm{L}$. Lycopene compounds were detected at $240 \mathrm{~nm}$.

\section{Microbiological analysis of watermelon juices}

The watermelon juices were subjected to a microbiological analysis to count microorganisms such as mesophilic aerobic flora (MAF), total coliforms (TC), and Staphylococcus aureus (SA).

One milliliter of each sample was taken aseptically and homogenized in $9 \mathrm{~mL}$ sterile peptone water for about $2 \mathrm{~min}$. Two dilutions $10^{-1}$ and $10^{-2}$ (using $1 \mathrm{~mL}$ of homogenates) were made in $9 \mathrm{~mL}$ sterile physiologic water and $1 \mathrm{~mL}$ of each decimal dilution was inoculated in duplicate on specific culture media for the numbering of the germs retained. The different culture media used were prepared according to the manufacturers' instructions. MAF were counted on Plate count agar (PCA) after incubation at $30^{\circ} \mathrm{C}$ for 72 $\mathrm{h}$ as recommended in NF/ISO 4833: 2003; TC were numbered on violet red neutral bile lactose (VRBL) agar after incubation at $30^{\circ} \mathrm{C}$ for $24 \mathrm{~h}$ as described in ISO 4832: 2006 and SA were counted on Baird-parker agar after incubation at $37^{\circ} \mathrm{c}$ for $24 \mathrm{~h}$ according to the French standard NF/ISO 6888: 2004. Counts of visible colonies were made and expressed as colony forming units per gram of sample (CFU/g).

\section{Sensory evaluation of watermelon juices}

The organoleptic properties of watermelon juices were determined by a set of external (color, texture) and internal (odor, sweetness, acidity and overall flavor) characteristics. The preferences of naïve consumers were achieved using a hedonic test. The hedonic test of these watermelon juices was carried out in a clean room, with a panel of 65 subjects. Two samples coded A and B were presented.

\section{Statistical processing of data}

All experiments were performed in duplicate and the averages of the data were statistically analysed using the STATISTICA 7.1 software. Analysis of Variance (ANOVA) was used to test the level of significance at $\mathrm{P}<0.05$. To separate the different samples, multiple comparison tests (Duncan) were conducted. 


\section{RESULTS AND DISCUSSION}

\section{Physicochemical characteristics of watermelon juice}

The physicochemical characteristics $(\mathrm{pH}$, Brix degree, ash, dry matter, titratable acidity, reducing sugar) of unpasteurized and pasteurized watermelon juice as a function of time are shown in Figure- 2 .

$\mathrm{pH}$ is one of the main quality characteristics that describes the stability of bioactive compounds in fruit juice [17].

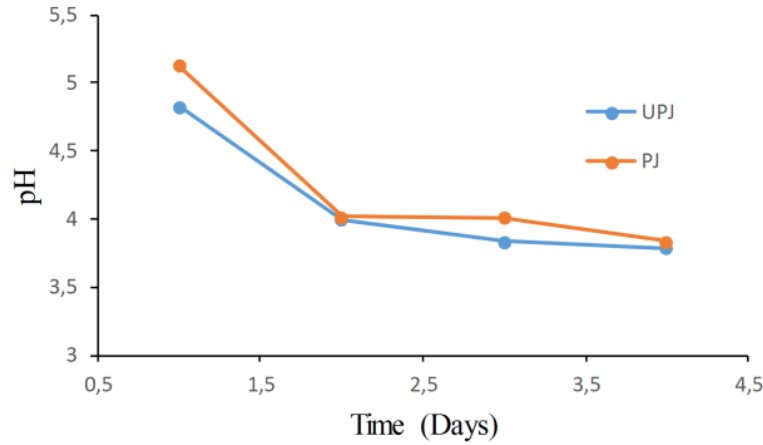

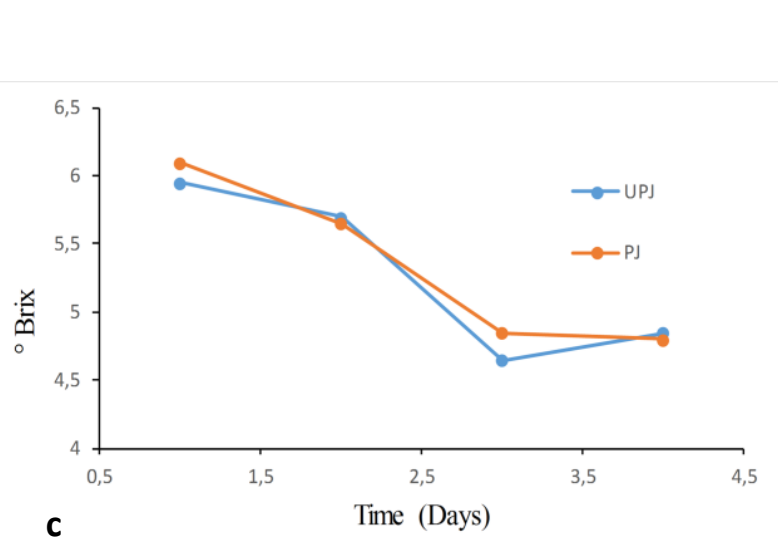

C

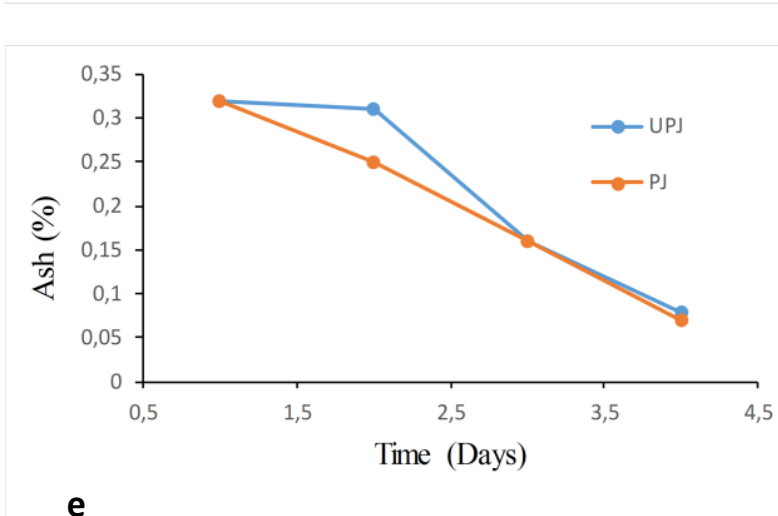

e

a
Indeed, the $\mathrm{pH}$ values of unpasteurized juice varied between 4.83 and 3.78 and that of pasteurized juice varied from 5.13 to 3.84 after four days (Fig-2a). These values of $\mathrm{pH}$ seem to decrease over time. The result shows that the $\mathrm{pH}$ values of the two juices were not significantly different. This drop in $\mathrm{pH}$ makes the juices more acidic. These $\mathrm{pH}$ values below the ideal maximum $\mathrm{pH}$ (4.6) are therefore very beneficial for the preservation of the juices produced $[13,18,19]$. This decrease in $\mathrm{pH}$ as the days of storage increased could be due to the breakdown of sugar by fermentation process leading to the production of acidic components [20].

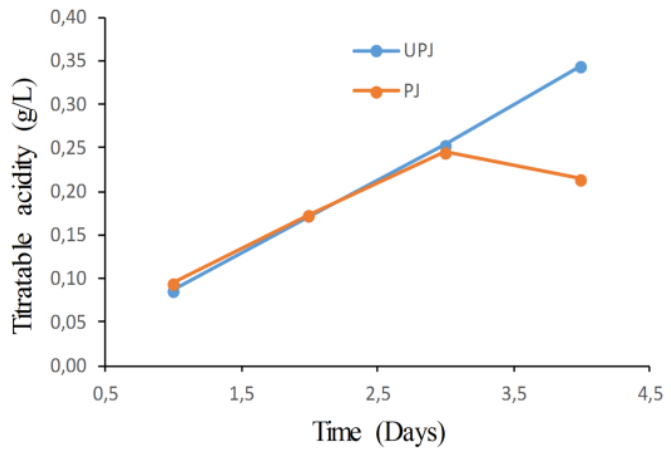

b
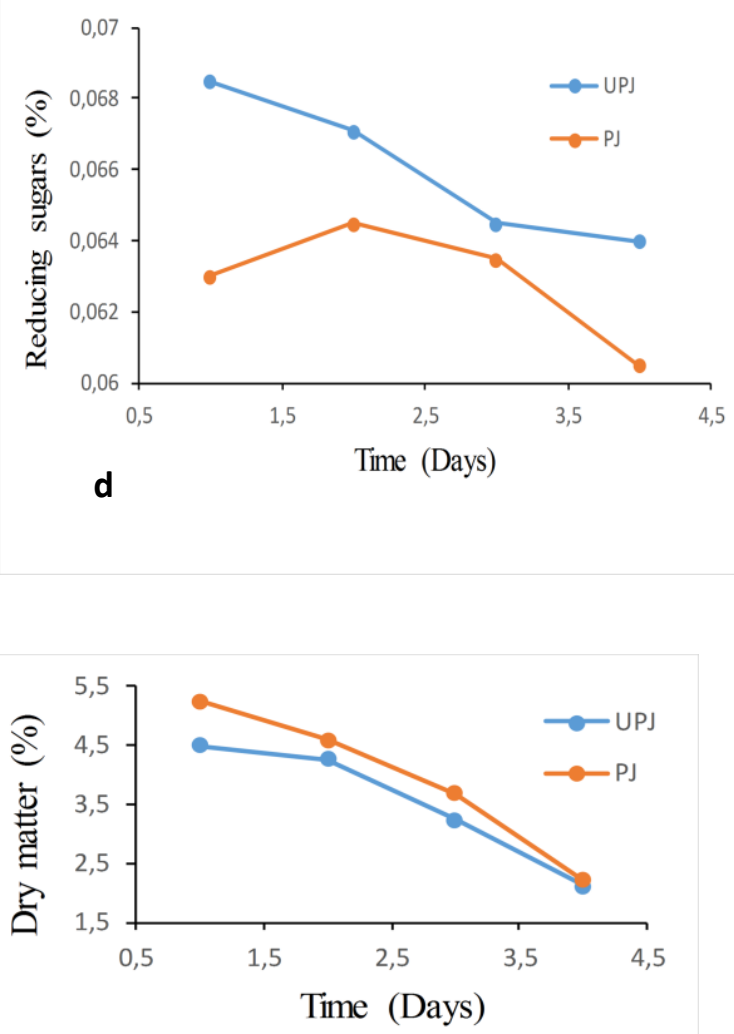

f

\footnotetext{
Fig-2: Evolution of physicochemical parameters (a: pH, b: Titrable acidity, c: Degree Brix, d: Reducing sugar, e: Ash, f: Dry matter) of unpasteurized and pasteurized watermelon juice as a function of time. UPJ: unpasteurized juice, PJ: pasteurized juice
} 
As regards titratable acidity, its levels were between $0.09 \mathrm{~g} / \mathrm{L}$ and $0.34 \mathrm{~g} / \mathrm{L}$ for unpasteurized juice and between $0.09 \mathrm{~g} / \mathrm{L}$ and $0.25 \mathrm{~g} / \mathrm{L}$ for pasteurized juice (Fig-2b). Analysis of variance showed that there was no significant difference. These results showed that the juices had low acidity. In fact, titratable acidity is a good estimator of organic acid content. Therefore, this slight increase in acidity would reflect the presence of organic acids in both juices. This presence of organic acids seems to be at the origin of the decrease in flavor, sweetness and sweetening effect of juices [21]. The results were however different to those reported by Eke-Ejiofor et al., [22] and Martins et al., [23] respectively in pasteurized watermelon juice ( 0.08 to $0.12 \mathrm{~g} / \mathrm{mL}$ ) and in concentrated watermelon juice $(0.070$ to $0.073 \mathrm{~g} / \mathrm{mL})$. These results show the correlation between the $\mathrm{pH}$ value and that of the titratable acidity of watermelon juice. When free acidity increase, $\mathrm{pH}$ decrease.

The Brix value reflects the amount of sugar present in the juice expressed in terms of the percentage of the sucrose content. ${ }^{\circ}$ Brix contents were between 5.95 and $4.65^{\circ}$ Brix for unpasteurized juice and between 6 and $4.8^{\circ}$ Brix for pasteurized juice with time (Fig-2c). Indeed, the results of analyze revealed that ${ }^{\circ} \mathrm{Brix}$ values decrease over time for both unpasteurized and pasteurized juice. These values indicate that these juices are relatively sweet since they are below those declared by the FDA (Food and Drug) for watermelon juice, between approximately 6 and $8^{\circ}$ Brix [24].

The contents of reducing sugars in watermelon juice were very low. The amounts obtained were between 0.069 and $0.064 \%$ in unpasteurized juice and between 0.064 and $0.061 \%$ for pasteurized juice after four days (Fig-2d). The results show no significant difference between them. The contents of reducing sugar vary very little one juice to another. However, the reason for this decrease in reducing sugar in juices could be due to the breakdown of sugar by yeast and other microorganisms during storage.

The ash contents of watermelon juice were low. They ranged between 0.32 and $0.08 \%$ for unpasteurized juice and between 0.32 and $0.07 \%$ for pasteurized juice during storage (Fig. 2e). Statistical analysis for this parameter did not show a significant difference $(p>0.05)$. A decrease in ash content was observed for both types of production during their storage. This decrease could be related to the action of enzymes in juices and moisture content.

As for the dry matter, its contents varied between 4.49 and $2.12 \%$ for unpasteurized juice and between 5.25 and $2.21 \%$ for pasteurized juice (Fig-2f). Indeed, the low dry matter contents obtained in the studied juices imply that watermelon juice contains high moisture content. In addition, these levels drop over time. Water directly affects the quality of prepared products as well as their storage. This high water content could be used to meet the need of hydration of individuals that require high body fluid [20].

\section{Vitamin $\mathrm{C}$ and Lycopene content}

The results relating to the antioxidants (vitamin $\mathrm{C}$ and lycopene) of the two types of juice are given in Table-1. The vitamin $\mathrm{C}$ content of pasteurized juice $(2.45 \mathrm{~g} / 100 \mathrm{~mL})$ is lower than that of unpasteurized juice $(7.57 \mathrm{~g} / 100 \mathrm{~mL})$. There is a significant reduction in the content of vitamin $\mathrm{C}$, showing its degradation in the processed juice. Indeed, this difference could be due to the effect of temperature. Heat treatments influence the vitamin $\mathrm{C}$ content in watermelon juice. According some previous works, vitamin $\mathrm{C}$ is very sensitive to pasteurization and providing an indication of the loss of other vitamins $[25,26]$.

Regarding the lycopene content of watermelon juices, the results show that the juices studied have low lycopene content. It varied between $0.055 \mathrm{mg} / 100 \mathrm{~mL}$ (unpasteurized juice) and $0.047 \mathrm{mg} / 100 \mathrm{~mL}$ (pasteurized juice). Significant difference was found between the juices $(P<0.05)$. Pasteurization therefore influences the lycopene content. According to Rawson et al., [27], a high temperature can lead to significant fragmentation of lycopene. Aganovic et al., [28] also showed that lycopene degradation is the fact of Maillard reactions and Strecker degradation products detected in the thermal treatment $\left(75^{\circ} \mathrm{C}\right.$ for $\left.45 \mathrm{~s}\right)$ of watermelon juice.

Table-1: Antioxidant content of watermelon juice

\begin{tabular}{|l|l|l|}
\hline Type of juices & Vitamin C $\mathbf{~ g / 1 0 0 ~} \mathbf{~ m L})$ & Lycopene $(\mathbf{m g} / \mathbf{1 0 0} \mathbf{~ m L})$ \\
\hline UPJ & $7.57 \pm 0.03^{\mathrm{a}}$ & $0.055 \pm 0.00^{\mathrm{a}}$ \\
\hline PJ & $2.45 \pm 0.04^{\mathrm{b}}$ & $0.047 \pm 0.00^{\mathrm{b}}$ \\
\hline
\end{tabular}

Values are averages \pm standard deviation of replicate determinations $(n=2)$. Means not followed by the same superscript letters in the same column are significantly different $(\mathrm{P}<0.05)$. UPJ: unpasteurized juice and PJ: pasteurized juice

\section{Microbiological quality of watermelon juice}

The results obtained from the evaluation of the hygienic and sanitary quality of watermelon juice are presented in Table-2. The number detecded for the mesophilic aerobic germs was $13 \mathrm{UFC} / \mathrm{mL}$ for unpasteurized juice and $7 \mathrm{Ufc} / \mathrm{ml}$ for pasteurized juice. Results also revealed an absence of coliforms and 
Staphylococcus aureus. By comparing the results obtained with French regulations, the results of microbiological analyzes show that the juices are of satisfactory quality compared to germs witnesses of faecal and cutaneous-mucous membrane contamination. The results also indicate that the production and processing technologies used are efficient and make it possible to obtain a juice of satisfactory hygienic quality compared to the aforementioned germs. The absence of pathogenic germs indicates that there is no proven health risk for the consumer.

Table-2: Microbiological evaluation of watermelon juices

\begin{tabular}{|l|l|l|l|}
\hline \multirow{2}{*}{ Watermelon juices } & \multicolumn{3}{|c|}{ Microorganisms (CFU/mL) } \\
\cline { 2 - 4 } & MAG & TC & SA \\
\hline UPJ & 13 & Absence & Absence \\
\hline PJ & 7 & Absence & Absence \\
\hline Microbiological criteria (E.U. 2005) & - & 10 & Absence \\
\hline
\end{tabular}

UPJ: unpasteurized juice, PJ: pasteurized juice, E. U.: European Union, MAG : Mesophilic aerobic germs, TC: Total coliforms, SA: Staphylococcus aureus

\section{Organoleptic characteristics of watermelon juice} The organoleptic characteristics of unpasteurized juices are different from those of pasteurized juices (Table-3). The perceptions of the descriptors vary greatly according to the criteria of color, smell, sweetness, acidity, texture and overall flavor. Individual differences imply variations in the response of different subjects to the same stimulus. Indeed, the grade attributed to the color of unpasteurized juices is $3.00 \pm 1.52$ and that of pasteurized juice is $2.00 \pm 1.30$. Likewise, the score for the smell of unpasteurized juice is $5.72 \pm 1.47$ and that of pasteurized juice is $3.87 \pm 1.27$. For sweetness, scores of $6.12 \pm 1.51$ for unpasteurized juices and 4.93 \pm 1.43 for pasteurized juice were recorded. Statistical analysis indicates a significant difference between the scores assigned to the characteristics: odor, color and sweetness of pasteurized and unpasteurized juices $(\mathrm{p}<$ 0.05). The scores obtained for the acidity, texture and overall flavor of the pasteurized juice and the unpasteurized juice are similar. Indeed, the score attributed to the acid character is $6.39 \pm 1.45$ for pasteurized juice and $5.72 \pm 1.47$ for unpasteurized juice. Regarding the texture character, the scores are $4.93 \pm 1.43$ for the pasteurized juice and $6.12 \pm 1.51$ for the unpasteurized juice. As for the flavor score, it is $6.12 \pm 1.52$ for unpasteurized juice and $5.42 \pm 1.43$ for pasteurized juice. Statistical analysis does not indicate any significant difference between the scores assigned to the acidity, texture and flavor characteristics of pasteurized and unpasteurized juices $(\mathrm{p}>0.05)$.

Table-3: Organoleptic characteristics of watermelon juice

\begin{tabular}{|l|l|l|l|l|l|l|}
\hline Type of juice & Color & Smell & Sweetness & Acidity & Texture & Flavor \\
\hline UPJ & $3.00 \pm 1.52^{\mathrm{a}}$ & $5.72 \pm 1.47^{\mathrm{c}}$ & $6.12 \pm 1.51^{\mathrm{b}}$ & $5.96 \pm 1.47^{\mathrm{d}}$ & $5.33 \pm 1.60^{\mathrm{e}}$ & $6.12 \pm 1.53^{\mathrm{f}}$ \\
\hline PJ & $2.00 \pm 1.30^{\mathrm{b}}$ & $3.87 \pm 1.27^{\mathrm{d}}$ & $4.93 \pm 1.43^{\mathrm{c}}$ & $6.39 \pm 1.45^{\mathrm{d}}$ & $4.63 \pm 1.65^{\mathrm{e}}$ & $5.42 \pm 1.43^{\mathrm{f}}$ \\
\hline
\end{tabular}

Values are averages \pm standard deviation of replicate determinations. Means not followed by the same superscript letters in the same column are significantly different $(\mathrm{P}<0.05)$. UPJ: Unpasteurized juice and PJ: Pasteurized juice

The differences between pasteurized juice and untreated juice are believed to be due to the effect of heat treatment which changed the color, smell, and sweetening effect of the juice. These results are in agreement with those of Eke-Ejiofor et al., [22] for $100 \%$ watermelon. However, as Dossou et al., [29], the quality of the juice is based on organoleptic criteria that have noticed it with their studies on the production of tomato paste. In addition, color and appearance are the first characteristics a consumer sees when shopping in a supermarket. Color can influence a consumer's purchase intention [30].

\section{CONCLUSION}

The present study was devoted to the evaluation of the physicochemical, microbiological and organoleptic characteristics of unpasteurized and pasteurized watermelon juice. The results revealed that the watermelon juices produced exhibit satisfactory physicochemical properties, bioactive compounds, microbiological quality and sensory benefit. However, pasteurization reduced the levels of vitamin $\mathrm{C}$ and lycopene. Also, the study of the microbiological quality of pasteurized and unpasteurized juices shows an absence of mesophilic aerobic germs, total coliforms and Staphylococcus aureus. On the other hand, watermelon juices have good acceptability.

\section{REFERENCES}

1. Hamzah, N., Wan Ishak, W. R., \& Rahman, N. A. (2018). Nutritional and pharmacological properties of agroindustrial by-products from commonly consumed fruits. SDRP Journal of Food Science \& Technology, 3(4), 1-21.

2. WHO. (2002). Rapport sur la santé dans le monde, 2002 - Réduire les risques et promouvoir une vie saine, Genève, Organisation mondiale de la Santé 2002, 50 . 
3. Grigoras, C. G. (2012). Valorisation des fruits et sous-produits de l'industrie de transformation des fruits par extraction des composés bioactifs. Thèse de Doctorat, Université d'Ornéans (France), 143.

4. Pitrat, M., Chauvet, M., \& Foury, C. (1999). Diversity, history and production of cultivated cucurbits. Acta Horticulturae, 492(1), 21-28.

5. FAO (2016). Food and Agriculture Organisation. Institution spécialisée des Nations Unies, Agricultural Production Primary Crops. at://www.fao.org. Accessed 8 February, 2019.

6. Choudhury, B. R., Haldhar, S. M., Maheshwari, S. K., Bhargava, R., \& Sharma, S. K. (2015). Phytochemicals and antioxidants in watermelon (Citrullus lanatus) genotypes under hot arid region. Indian Journal of Agricultural Sciences, 85(3), 122-125.

7. Edwards, A. J., Vinyard, B. T., Wiley, E. R., Brown, E. D., Collins, J. K., Perkin-Veazie, P., Baker, R. A., \& Clevidence, B. A. (2003). Consumption of watermelon juice increases plasma concentrations of lycopene and $\beta$-carotene in humans. Journal Nutrition, 133(4), 1043-1050.

8. Lum, T., Connolly, M., Marx, A., Beidler, J., Hooshmand, S., Kern, M., Liu, C., \& Hong, M. Y. (2019). Effect of fresh watermelon consumption on the acute satiety response and cardiometabolic risk factors in overweight and obese adults. Nutrients, 11(3), 595.

9. Duduyemi, O., Adebanjo S.A., \& Oluoti, K. (2013). Extraction and determination of physicochemical properties of watermelon seed oil (Citrullus lanatus L) For Relevant Uses. International Journal of Scientific \& Technology Research, 2(8), 66-68.

10. Gbotto, A. A., Koffi, K. K., Bi, N. D. F., Bi, S. T. D., Tro, H. H., Baudoin, J-P., \& Zoro Bi, I. A. (2016). Morphological diversity in oleaginous watermelon (Citrullus mucosospermus) from the Nangui Abrogoua University germplasm collection. African Journal of Biotechnology, 15, 917-929.

11. Déclert, C. (1990). Manuel de phytopathologie maraîchère tropicale. Cultures de Côte d'Ivoire, Éditions de l'ORSTOM Paris (France), 332.

12. Anonymous. (2002). Rapport d'étude du Ministère de l'Agriculture et de la Pêche Maritime-Direction de la Stratégie et des Statistiques. Culture de la pastèque au Maroc et Filière pastèque dans le monde, 29.

13. Amiot, J., Fournier, S., Lebeuf, Y., Paquin, P., \& Simpson, R. (2002). Composition, propriétés physico-chiques, valeur nutritive, qualité technologique et techniques d'analyse du lait. In Science et Technologie du lait (Eds.), Transformation du lait (pp. 1-68). Presses Internationales Polytechnique.

14. AOAC. (1990). Official methods of Analysis of the Association of Official Analytical Chemists
Chemists International, (16th Eds). AOAC International Arlington, VA, 250.

15. AOAC (Association of Official Analytical Chemists). (2006). Official Methods of Analysis, Association of Official Analytical Chemists. Washington, DC. Ed. 18th, USA (Virginia), 201.

16. Bernfeld, P. (1955). Amylase $\alpha$ and $\beta$, Methods in Enzymology. Academic Press Inc New York, 1: 149-158.

17. Sanchez- Moreno, C., Plaza, L., De Ancos, B., \& Cano, M. P. (2006). Nutritional characterization of commercial traditional pasteurized tomato juices: Carotenoids, vitamin $\mathrm{C}$ and radical scavenging capacity. Food Chemistry, 98, 749- 756.

18. Codex Alimentarius. (2005). Normes générale codex pour les jus et les nectars de fruits. Codex. STAN 247-2005, 19.

19. Sadler, G. D., \& Murphy, P. A. (2010). pH and titratable acidity. Food analysis S. S. Nielsen, (Eds.), Boston, MA: Springer US.

20. Umelo, C. M., Odimegwu, E. N., Uzukwu, A. E., Eluchie, C. N., Nwachukwu, C. N., Nwaobi, C. C., Amaraegbulem, K. U., \& Nwakwalam, N. C. (2014). Effect of pasteurization on the physicochemical, nutritional and sensory properties of watermelon (Citrullus lanatus) juice. European International Journal of Applied Science and Technology, 1(6), 48-60.

21. Lampe, J. W. (1999). Health effects of vegetables and fruit: assessing mechanisms of action in human experimental studies. American Journal of Clinical Nutrtion, 70(3), 475-490.

22. Eke-Ejiofor, J., Banigo, E. B., \& Victor-Uku, E. (2016). Product Development, sensory and Chemical composition of spiced watermelon juice. International Journal of Biotechnology and Food Science, 4(2), 15-21.

23. Martins, C. P. C., Ferreiraa, M. V. S., Esmerino, E. A., Moraes, J., Pimentel, T. C., Rocha, R. S., Freitas, M. Q., Santos, J. S., Ranadheera, C. S., Rosa, L. S., Teodoro, A. J., Mathias, S. P., Silva, M. C., Raices, R. S. L., Couto, S. R. M., Granato, D., \& Cruz, A. G. (2018). Chemical, sensory, and functional properties of whey-based popsicles manufactured with watermelon juice concentrated at different temperatures. Food Chemistry, 255, 58-66.

24. Marks, S. M., Lunt, M., \& Mattson, P. (2003). Method of Making a Commercial packaged watermelon juice drink. United States. Watermelon works LLC (Woodland, CA). Patent $n^{\circ} 6589581$.

25. Marfil, P., Santos, E., \& Telis V. (2008). Ascorbic acid degradation kinetics. In tomatoes at different drying conditions. LWT-Food Science and Technology, 41(9), 1642-1647.

26. Zulueta, A., Esteve, M. J., \& Frigola, A. (2010). Ascorbic acid in juice-milk beverage treated by high intensity pulsed electric fields and its stability during storage. Journal of Innovative Food 
Science and Emerging Technologies, 11(2010), 84-90.

27. Rawson, A., Tiwari, B. K., Patras, A., Brunton, N., Brennan, C., Cullen, P. J., \& O'Donnell, C. (2011).

Effect of thermosonication on bioactive compounds in watermelon juice. Food Research International, 44, 1168-1173.

28. Aganovic, K., Grauwet, T., Siemer, C., Toepfl, S., Heinz, V., Hendrickx, M., \& Loey, A. V. (2016). Headspace fingerprinting and sensory evaluation to discriminate between traditional and alternative pasteurization of watermelon juice. European Food Research and Technology, 242(5), 787-803.

29. Dossou, J., Soule, I., \& Montcho, M. (2007). Evaluation des caractéristiques physicochimiques et sensorielles de la purée de tomate locale produite à petite échelle au Benin. Tropicultura, 25, 119-125.

30. Francis, F. (1995). Quality as Influenced by Color. Food Quality and Preference, 6(3), 149-155. 